\section{PEMASARAN JASA}

Sektor jasa merupakan salah satu bidang yang memiliki prospek besar karena perkembangannya yang sangat pesat. Pemasaran berperan bagi perusahaan jasa tidak hanya sekadar memberikan informasi penting mengenai produk jasa yang ditawarkan perusahaan, tetapi juga sangat bermanfaat untuk memengaruhi dan membujuk konsumen untuk membeli jasa perusahaan dibanding pesaing.

Buku ini merupakan pedoman bagi mahasiswa, dosen maupun masyarakat umum yang berminat pada bidang pemasaran jasa. Buku ini diharapkan dapat memberikan petunjuk secara teoretis maupun praktis agar mahasiswa mendapatkan gambaran secara jelas dan aplikatif dalam memahami konsep pemasaran jasa. Pembahasan terdiri dari 10 bab yang mencakup konsep dasar jasa, jenis jasa, rancangan produk jasa, penyampaian jasa, manajemen permintaan dan penawaran jasa, harga dalam jasa, komunikasi pemasaran, kualitas jasa, perilaku konsumen jasa dan inovasi jasa sebagai keunggulan.

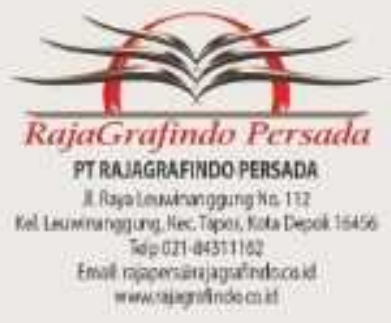

RAJAWALI PERS DIVII BUKU PERGURUAN TING

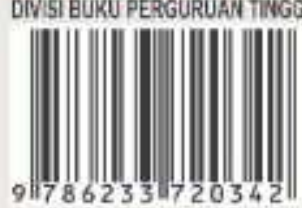

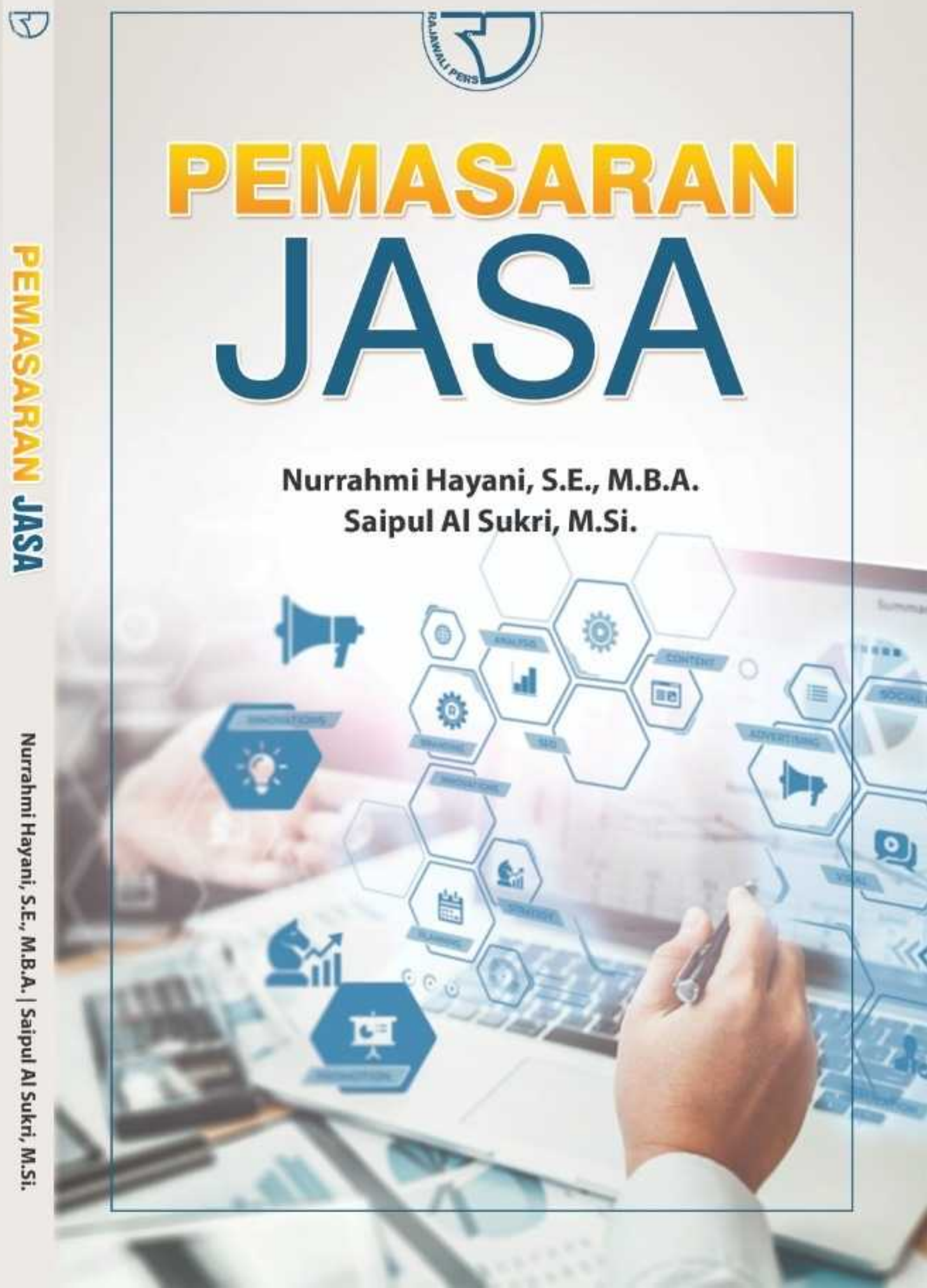




\section{PEMASARAN \\ JASA}




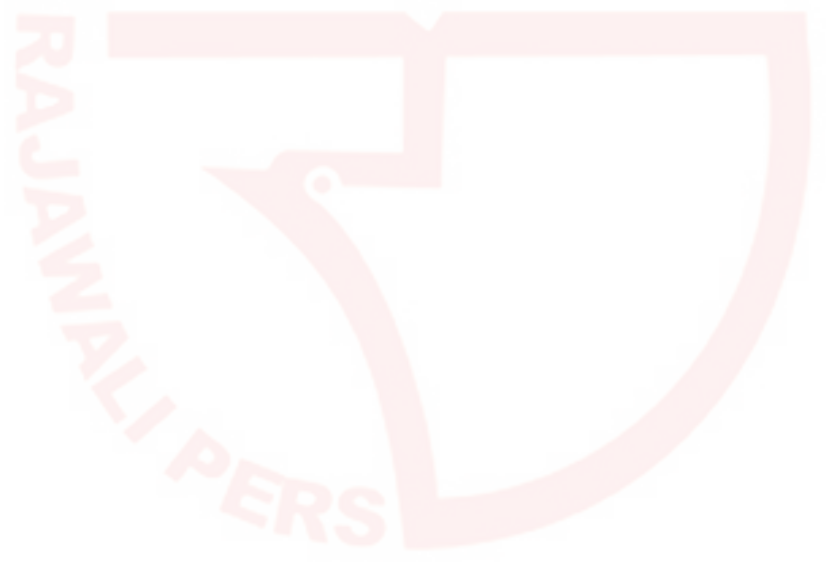




\section{PEMASARAN JASA}

Nurrahmi Hayani, S.E., M.B.A. Saipul Al Sukri, M.Si.

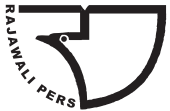

RAJAWALI PERS

Divisi Buku Perguruan Tinggi

PT RajaGrafindo Persada

D E P O K 
Perpustakaan Nasional: Katalog dalam terbitan (KDT)

Nurrahmi Hayani dan Saipul Al Sukri.

Pemasaran Jasa/Nurrahmi Hayani dan Saipul Al Sukri.

-Ed. 1, Cet. 1.-Depok: Rajawali Pers, 2021.

xvi, $150 \mathrm{hlm} ., 23 \mathrm{~cm}$.

Bibliografi: hlm. 133.

ISBN 978-623-372-034-2

Hak cipta 2021, pada penulis

Dilarang mengutip sebagian atau seluruh isi buku ini dengan cara apa pun, termasuk dengan cara penggunaan mesin fotokopi, tanpa izin sah dari penerbit

\subsection{RAJ}

Nurrahmi Hayani, S.E., M.B.A.

Saipul Al Sukri, M.Si.

PEMASARAN JASA

Cetakan ke-1, Oktober 2021

Hak penerbitan pada PT RajaGrafindo Persada, Depok

Copy Editor : Indi Vidyafi

Setter : Raziv Gandhi

Desain Cover : Tim RGP

Dicetak di Rajawali Printing

\section{PT RAJAGRAFINDO PERSADA}

Anggota IKAPI

Kantor Pusat:

Jl. Raya Leuwinanggung, No.112, Kel. Leuwinanggung, Kec. Tapos, Kota Depok 16456

Telepon: (021) $84311162-(021) 84311163$

E-mail : rajapers@rajagrafindo.co.id http://www.rajagrafindo.co.id

\footnotetext{
Perwakilan:

Jakarta-16956 Jl. Raya Leuwinanggung No. 112, Kel. Leuwinanggung, Kec. Tapos, Depok, Telp. (021) 84311162. Bandung-40243, J. H. Kurdi Timur No. 8 Komplek Kurdi, Telp. 022-5206202. Yogyakarta-Perum. Pondok Soragan Indah Blok A1, Jl. Soragan, Ngestiharjo, Kasihan, Bantul, Telp. 0274-625093. Surabaya-60118, Jl. Rungkut Harapan Blok A No. 09, Telp. 031-8700819. Palembang-30137, Jl. Macan Kumbang III No. 10/4459 RT 78 Kel. Demang Lebar Daun, Telp. 0711-445062. Pekanbaru-28294, Perum De' Diandra Land Blok C 1 No. 1, Jl. Kartama Marpoyan Damai, Telp. 0761-65807. Medan-20144, Jl. Eka Rasmi Gg. Eka Rossa No. 3A Blok A Komplek Johor Residence Kec. Medan Johor, Telp. 061-7871546. Makassar-90221, Jl. Sultan Alauddin Komp. Bumi Permata Hijau Bumi 14 Blok A14 No. 3, Telp. 0411-861618. Banjarmasin-70114, Jl. Bali No. 31 Rt 05, Telp. 0511-3352060. Bali, Jl. Imam Bonjol Gg 100/V No. 2, Denpasar Telp. (0361) 8607995. Bandar Lampung-35115, Perum. Bilabong Jaya Block B8 No. 3 Susunan Baru, Langkapura, Hp. 081299047094.
} 
"Jika kamu tak sanggup menahan lelahnya belajar,

maka kamu harus sanggup menahan perihnya kebodohan" (Imam Syafi'i Rahimahullah

dalam Kitab Diwan Al-Imam Asy-Syafi'i)

\section{Untuk Keluarga}

dan

Mahasiswa/i tercinta 


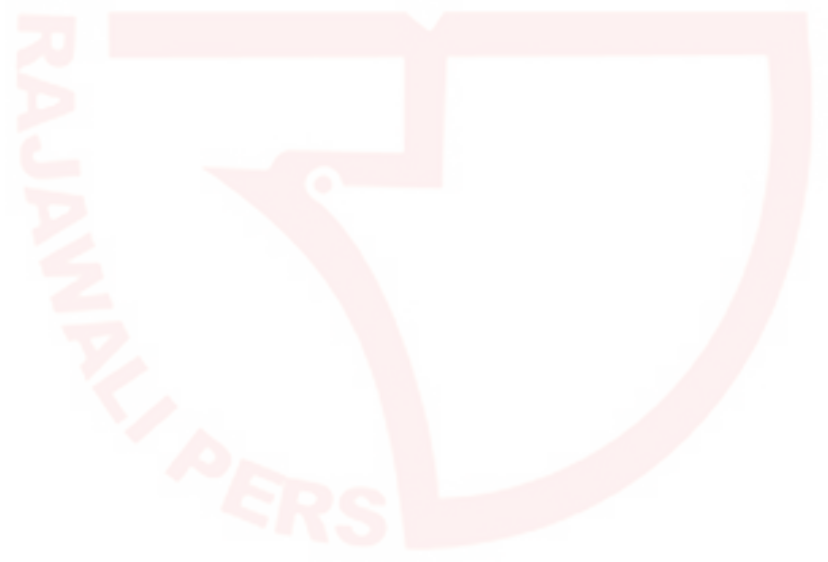




\section{PRAKATA}

Bismillahirrahmanirrahim

Assalamualaikum wa rahmatullah wa barakatuh

Syukur kepada Allah Subhanahu wa ta'ala atas selesainya pembuatan buku "Pemasaran Jasa" bagi mahasiswa Fakultas Ekonomi dan Ilmu Sosial Universitas Islam Negeri Sultan Syarif Kasim Riau pada tahun 2021. Selawat dan salam semoga terlimpahkan kepada Nabi Muhammad Sallallahu 'alaihi wasallam.

Sektor jasa merupakan salah satu bidang yang memiliki prospek besar karena perkembangannya yang sangat pesat. Pemasaran berperan bagi perusahaan jasa tidak hanya sekadar memberikan informasi penting mengenai produk jasa yang ditawarkan perusahaan, tetapi juga sangat bermanfaat untuk memengaruhi dan membujuk konsumen untuk membeli jasa perusahaan dibanding pesaing.

Buku ini merupakan pedoman bagi mahasiswa Jurusan Manajemen konsentrasi Pemasaran dalam perkuliahan serta memberikan petunjuk praktis agar mahasiswa mendapatkan gambaran secara jelas dan aplikatif dalam memahami konsep pemasaran jasa. 
Kami menyadari masih terdapat kekurangan dalam buku ini untuk itu kritik dan saran terhadap penyempurnaan buku ini sangat diharapkan. Semoga buku ini dapat memberi manfaat bagi mahasiswa Jurusan Manajemen khususnya dan bagi semua pihak yang membutuhkan.

Wassalamualaikum wa rahmatullah wa barakatuh.

Pekanbaru, Agustus 2021

Penulis 


\section{DAFTAR ISI}

PRAKATA

vii

DAFTAR ISI

ix

DAFTAR TABEL

xiii

DAFTAR GAMBAR

$\mathrm{XV}$

BAB 1 KONSEP DASAR JASA

A. Pengertian Pemasaran 1

B. Pengertian Jasa $\quad 7$

C. Faktor Pendorong Perkembangan Industri Jasa 9

$\begin{array}{ll}\text { BAB } 2 \text { JENIS JASA } & 13\end{array}$

A. Karakteristik Jasa 13

B. Tingkatan Jasa 17

C. Klasifikasi Jasa 18

D. Bauran Pemasaran Jasa 7P 22

BAB 3 RANCANGAN PRODUK JASA 27
A. Unsur Penawaran Jasa
27
B. Flower of Services 29
C. Strategi Produk Jasa 31 
A. Desain Penyampaian Jasa $\quad 35$

B. Alternatif Penyampaian Jasa 38

C. Service Blueprinting 39

D. Service Encounter $\quad 39$

E. Servicescape 41

F. Service Redesign 43

G. Saluran Distribusi Jasa 44

BAB 5 MANAJEMEN PERMINTAAN DAN PENAWARAN JASA 49
A. Strategi Mengelola Permintaan
B. Strategi Mengelola Penawaran
C. Strategi-Strategi untuk Menyesuaikan Permintaan dan Kapasitas
D. Manajemen Antrean
A. Penetapan Harga Jasa
B. Karakteristik Harga Jasa
C. Strategi Penetapan Harga Jasa

BAB 7 KOMUNIKASI PEMASARAN 77
A. Komunikasi Pemasaran Terintegrasi
B. Karakteristik Bauran Komunikasi Pemasaran
C. Bauran Komunikasi Pemasaran
A. Model Service Quality
B. Model Pengukuran Kualitas Jasa
C. Model-Model Alternatif 
BAB 9 PERILAKU KONSUMEN JASA
A. Harapan dan Pengalaman Konsumen
109
B. Keputusan Pembelian
112
C. Pemulihan Jasa
116

BAB 10 INOVASI JASA SEBAGAI KEUNGGULAN

119

A. Konsep Kepuasan Pelanggan 119

B. Relationship Marketing Orientation (RMO) 120

C. Strategi Membangun Loyalitas Pelanggan 121

D. Inovasi Jasa (Service Innovation) 126

E. Dampak Inovasi Jasa dalam Perusahaan 128

F. Teknologi Informasi dalam Jasa 129

DAFTAR PUSTAKA 133

GLOSARIUM 139

INDEKS 145

BIODATA PENULIS 149 


\section{DAFTAR TABEL}

Tabel 1.1 Perkembangan Konsep Pemasaran

Tabel 2.1 Karakteristik Jasa dan Implikasi Manajemen 16

Tabel 4.1 Elemen-Elemen Physical Evidence 42

Tabel 4.2 Tipologi Servicescape 42

Tabel 6.1 Strategi Penetapan Harga Jasa $\quad 74$

Tabel 7.1 Keunggulan dan Kelemahan Berbagai Macam Media 86

Tabel 7.2 Consumer Promotion, Trade Promotion and Salesforce Promotion 88

Tabel 7.3 Keunggulan dan Kelemahan Beberapa Jenis Promosi Penjualan 89

Tabel 8.1 Contoh Kuesioner Internet Retail Service Quality (IRSQ) 104

Tabel 8.2 Internal Service Quality 107 


\section{[Halaman ini sengaja dikosongkan]}




\section{DAFTAR GAMBAR}

Gambar 1.1 Hierarki Kebutuhan Maslow Beserta Contoh Produk Relevan

Gambar 2.1 Implikasi Intangibility Jasa

Gambar 2.2 Implikasi Inseparability Jasa

Gambar 2.3 Kategori Bauran Jasa

Gambar 2.4 Klasifikasi Jasa Berdasarkan Metode

Penyampaian Jasa

Gambar 3.1 Tiga Level Produk pada Penawaran Mobil

Gambar 3.2 Tiga Level Produk pada Perusahaan Penerbangan Qantas

Gambar 3.3 The Flower of Services

Gambar 3.4 Matriks Ekspansi Pasar/Produk

Gambar 4.1 Service Blueprint for a Fast Food Outlet

Gambar 4.2 Pilihan Saluran Distribusi Jasa

Gambar 5.1 Strategi-Strategi untuk Menyesuaikan Permintaan dan Penawaran Jasa

Gambar 7.1 Empat Elemen Dasar Marketing Communication Mix 


\section{[Halaman ini sengaja dikosongkan]}




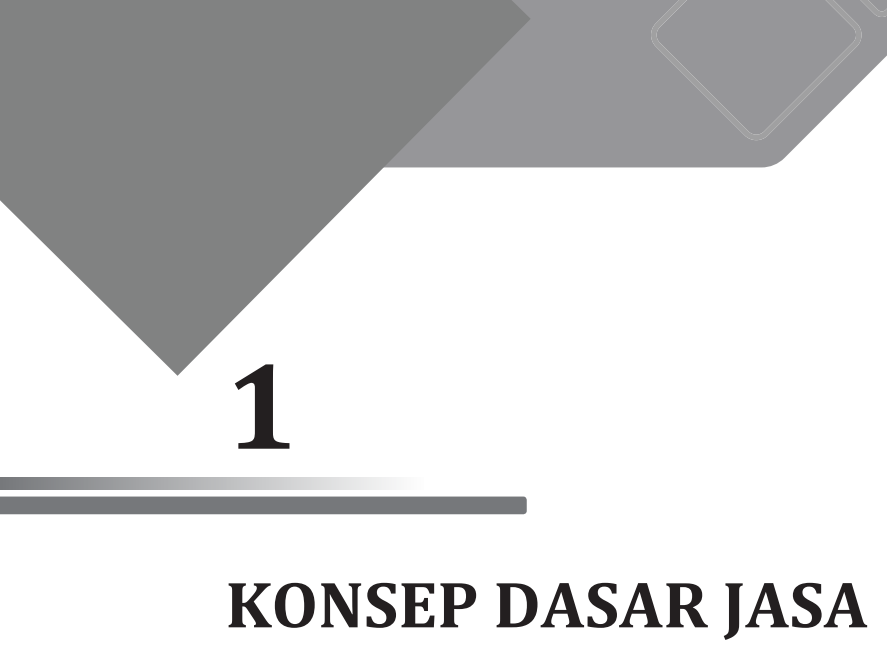

\section{KONSEP DASAR JASA}

\section{A. Pengertian Pemasaran}

Sektor jasa merupakan salah satu bidang yang memiliki prospek besar karena perkembangannya yang sangat pesat. Pemasaran berperan bagi perusahaan jasa tidak hanya sekadar memberikan informasi penting mengenai produk jasa yang ditawarkan perusahaan, tetapi juga sangat bermanfaat untuk memengaruhi dan membujuk konsumen untuk membeli jasa perusahaan dibanding pesaing.

Menurut American Marketing Association (2007), pemasaran diartikan sebagai aktivitas, serangkaian institusi, dan proses penciptaan, mengomunikasikan, menyampaikan, dan mempertukarkan tawaran yang bernilai bagi pelanggan, klien, mitra dan masyarakat luas.

Pada umumnya setiap perusahaan menganut salah satu konsep atau filosofi pemasaran, yaitu falsafah atau anggapan yang diyakini perusahaan sebagai dasar dari setiap kegiatannya dalam memuaskan kebutuhan dan keinginan konsumen. Pemilihan dan penerapan konsep pemasaran tertentu dipengaruhi beberapa faktor, di antaranya nilai-nilai dan visi manajemen, lingkungan internal dan lingkungan eksternal perusahaan. Perkembangan konsep pemasaran meliputi: 


\section{Konsep Produksi}

Pemasar yang berpegang pada konsep ini berorientasi pada proses produksi/operasi (internal). Asumsi yang diyakini adalah bahwa konsumen hanya akan membeli produk-produk yang murah dan gampang diperoleh. Dengan demikian, kegiatan organisasi harus difokuskan pada efisiensi biaya (produksi) dan ketersediaan produk (distribusi) agar perusahaan meraih keuntungan.

\section{Konsep Produk}

Dalam konsep ini, pemasar beranggapan bahwa konsumen lebih menghendaki produk-produk yang memiliki kualitas, kinerja, fitur (fetures) atau penampilan superior. Konsekuensinya, pencapaian tujuan bisnis perusahaan dilakukan melalui inovasi produk, riset dan pengembangan serta pengendalian secara berkesinambungan.

\section{Konsep Penjualan}

Konsep ini merupakan konsep yang berorientasi pada tingkat penjualan (internal), di mana pemasar beranggapan bahwa konsumen harus dipengaruhi (bilamana perlu dibujuk) agar penjualan dapat meningkat, sehingga tercapai laba maksimum sebagaimana menjadi tujuan perusahaan. Dengan demikian, fokus kegiatan pemasaran adalah usahausaha memperbaiki teknik-teknik penjualan dan kegiatan promosi secara intensif dan agresif agar mampu memengaruhi dan membujuk konsumen untuk membeli, sehingga pada gilirannya penjualan dapat meningkat.

\section{Konsep Pemasaran}

Berbeda dengan 3 konsep terdahulu yang berorientasi pada lingkungan internal, konsep pemasaran berorientasi pada pelanggan (lingkungan eksternal) dengan anggapan bahwa konsumen hanya akan bersedia membeli produk-produk yang mampu memenuhi kebutuhan dan keinginannya serta memberikan kepuasan. Implikasinya, fokus aktivitas pemasaran dalam rangka mewujudkan tujuan perusahaan adalah berusaha memuaskan pelanggan melalui pemahaman perilaku konsumen secara menyeluruh yang dijabarkan dalam kegiatan pemasaran yang mengintegrasikan kegiatan-kegiatan fungsional lainnya (seperti 
produksi/operasi, keuangan, personalia, riset, dan pengembangan) secara lebih efektif dan efisien dibandingkan para pesaing.

\section{Konsep Pemasaran Sosial}

Pemasaran yang menganut konsep ini beranggapan bahwa konsumen hanya bersedia membeli produk-produk yang mampu memuaskan kebutuhan dan keinginannya serta berkontribusi pada kesejahteraan lingkungan sosial konsumen. Tujuan aktivitas pemasaran adalah berusaha memenuhi kebutuhan masyarakat sekaligus memperbaiki hubungan antara produsen dan masyarakat demi peningkatan kesejahteraan pihak-pihak terkait.

Tabel 1.1 Perkembangan Konsep Pemasaran

\begin{tabular}{|l|l|l|}
\hline \multicolumn{1}{|c|}{ Konsep } & \multicolumn{1}{|c|}{ Fokus } & \multicolumn{1}{c|}{ Anggapan } \\
\hline Produksi & $\begin{array}{l}\text { Penekanan biaya } \\
\text { produksi dan peningkatan } \\
\text { ketersediaan produk }\end{array}$ & $\begin{array}{l}\text { Harga murah dan distrubusi intensif } \\
\text { merupakan dasar pertimbangan utama } \\
\text { pembelian. }\end{array}$ \\
\hline Produk & Inovasi produk & $\begin{array}{l}\text { Karakteristik, kinerja dan kualitas } \\
\text { superior merupakan pertimbangan } \\
\text { utama konsumen dalam melakukan } \\
\text { pembelian. }\end{array}$ \\
\hline Penjualan & Peningkatan penjualan & $\begin{array}{l}\text { Usaha-usaha penjualan dan promosi } \\
\text { harus lebih aktif dan agresif dalam } \\
\text { rangka memengaruhi konsumen agar } \\
\text { melakukan pembelian. }\end{array}$ \\
\hline Pemasaran & Kepuasan pelanggan & $\begin{array}{l}\text { Pembelian dan pembelian ulang akan } \\
\text { dilakukan apabila pelanggan (individual) } \\
\text { mendapatkan kepuasan dalam } \\
\text { pembelian. }\end{array}$ \\
\hline Pemasaran & $\begin{array}{l}\text { Kepuasan pelanggan dan } \\
\text { kesejahteraan masyarakat }\end{array}$ & $\begin{array}{l}\text { Pembelian dan pembelian ulang akan } \\
\text { dilakukan apabila pelanggan (individu } \\
\text { dan sosial) mendapatkan kepuasan } \\
\text { dalam pembelian. }\end{array}$ \\
\hline
\end{tabular}

Sumber: Tjiptono, Fandy (2014)

Fandy (2014) menyatakan bahwa dalam konteks pemasaran, kebutuhan (needs) dan keinginan (wants) dibedakan. Kebutuhan merupakan suatu keadaan merasa tidak memiliki kepuasan dasar. Kebutuhan melekat pada sifat dasar manusia, sehingga tidak gampang berubah. Menurut Abraham Maslow, kebutuhan dasar manusia 